\title{
Satisfaction of women with health service provider in outpatient department of Obstetrics and Gynecology at a Tertiary care hospital
}

\author{
Khatun $\mathrm{A}^{1}$, Aktar $\mathrm{MN}^{2}$, Akter $\mathrm{FM}^{3}$, Nahar $\mathrm{K}^{4}$, Rahman $\mathrm{H}^{5}$
}

\begin{abstract}
Background: Patient's satisfaction over the health care services is very important issue in Bangladesh. Objective: The purpose of present study was to find out the level of satisfaction of women attending in the OPD of Obstetrics and Gynecology department at a tertiary care hospital in Dhaka. Methodology: This descriptive type of cross sectional study was carried out in the OPD of Obstetrics and Gynecology department at Dhaka Medical College from September 2011 to October 2011 for a period of one month. All the women attending in Obstetrics and Gynecology department in outdoor service at Dhaka Medical College Hospital, Dhaka with the age group of 22 to 40 years were selected as study population. A purposive sampling method was used to collect the data. Results: A total number of 200 cases were taken for this study. Highly satisfied over the services delivered by the doctors was reported in $135(65.8 \%)$ cases and service of nurses was satisfied $111(55.8 \%)$ of cases. Satisfactory waiting time (two hours) was $143(71.9 \%)$ of cases and the satisfactory hospital environment was $127(63.8 \%)$ of cases. Conclusion: In conclusion most of the women are satisfied to the treatment delivered by the doctors at the OPD of a tertiary care hospital. [J Shaheed Suhrawardy Med Coll, 2014;6(2):79-81]
\end{abstract}

Keywords: Satisfaction; Obstetrics \& Gynaecology; health services; OPD

Received: 1 December 2013; Reviewed: 19 February 2014; Accepted: 7 June 2014

\section{Introduction}

Patient's satisfaction is also known in Oliver's terms as Patient's fulfillment response ${ }^{1}$. It is a judgment that a health care gives services a pleasurable level of consumption related fulfillment. Bangladesh Government and its development partners have also acknowledged their concerns about the quality of health care services ${ }^{2}$. Concern over the quality of health care services in Bangladesh has led to loss of faith in Government hospitals. These lead to low utilization of public health facilities and increasing outflow of Bangladeshi patients to hospital in neighboring countries.

Under these circumstances, assessment of the countries quality of health care service has become imperative, in which patients must begin to play a greater role ${ }^{3}$. In developing countries like Bangladesh, few studies have sought patients' view on satisfaction with services. There is little effort to involve them in measuring satisfaction or defining health standards. Service orientation of doctors has strong factor influencing patients satisfactions in hospital. Service orientation of nurses is an important factor for ensuring patients satisfaction in Bangladesh, but dearth of nurses is a continuing problem. This Study attempts to identify the determinants of patient's satisfaction in outdoor hospital. The purpose of the present study was to assess the satisfaction level of women attending in outpatient department in Dhaka Medical College, Dhaka.

\section{Methodology}

This descriptive type of cross sectional study was carried out in the OPD of Obstetrics and Gynecology department at Dhaka Medical College from September 2011 to October 2011 for a period of one month. All the women attending in Obstetrics and Gynecology department in outdoor service at

1. Dr. Ashia Khatun, Assistant Professor, Department of Obstetrics \& Gynaecology, Shaheed Suhrawardy Medical College, Dhaka

2. Dr. Khairun Nahar, Department of Obstetrics \& Gynaecology, Shaheed Suhrawardy Medical College, Dhaka

3. Dr. Mst. Nurunnahar Aktar, Assistant Professor, Department of Obstetrics \& Gynaecology, Shaheed Suhrawardy Medical College, Dhaka

4. Dr. Fatema Mahbooba Akter, Junior Consultant, Department of Obstetrics \& Gynaecology, Shaheed Suhrawardy Medical College, Dhaka

5. Dr. Habibur Rahman, Lecturer, Department of Anatomy, Shaheed Suhrawardy Medical College, Dhaka

Corresponding Author: Dr. Ashia Khatun, Associate Professor, Department of Obstetrics \& Gynaecology, Shaheed Suhrawardy Medical College, Sher-E-Bangla Nagar, Dhaka-1207, Bangladesh; Email: dr.ashia-khatun@yahoo.com; Cell no.: +8801711671358

Conflict of Interest: There is no conflict of interest declared by all authors.

Contribution to authors: AK, MNA were contributed from preparation of protocol up to research works. FMA \& KN were prepared the manuscript. 
Dhaka Medical College Hospital, Dhaka with the age group of 22 to 40 years were selected as study population. A purposive sampling method was used to collect the data. The patients those are very sick and deny to give answer about satisfaction were excluded from this study. Data Analysis was done SPSS Version 16. Written Informed Consent was taken from each of the participant. The dependent variables of this study were the satisfaction of the women regarding the service doctors and nurses and facilities in outpatient department.

\section{Results}

Out of 200 cases most the age group was within 21 to 25 years of $52(26.1 \%)$ cases (Table 1). Opinion about services of Doctors was highly satisfied was $135(5.8 \%)$ of cases (Table 2) and service of Nurses was satisfied 111 (55.8\%) of cases (Table 3).

\section{Table 1: Distribution of respondents by age}

\begin{tabular}{lcc}
\hline Age groups & Frequency & Percent \\
\hline 16-20 Years & 39 & 19.6 \\
21-25 Years & $\mathbf{5 2}$ & $\mathbf{2 6 . 1}$ \\
26-30 Years & 44 & 0.1 \\
31-35 Years & 35 & 17.6 \\
36-40 Years & 19 & 9.5 \\
Above 41+ & 9 & 4.5 \\
Total & $\mathbf{1 9 9}$ & $\mathbf{1 0 0 . 0}$ \\
\hline
\end{tabular}

Satisfactory waiting time (two hours) was 143 (71.9\%) of cases (Table 4) and the satisfactory hospital environment was $127(63.8 \%)$ of cases (Table 5).

Table 2: Opinion of the respondents about service of doctor

\begin{tabular}{lcc}
\hline Level of Satisfaction & Frequency & Percent \\
\hline Highly Satisfied & 135 & 65.8 \\
Satisfied & 65 & 33.7 \\
Poorly satisfied & 2 & 0.5 \\
Total & $\mathbf{1 9 7}$ & $\mathbf{1 0 0 . 0}$ \\
\hline
\end{tabular}

\section{Discussion}

Improving patient satisfaction is a key element in strategies for improving the long-term economic viability of health care institutions. Patient satisfaction, defined as the client's overall positive evaluation of the health care services ${ }^{5}$, largely influences health care provider choice in health care sector ${ }^{6}$. Patients satisfied with the health care services of a particular hospital may tend to visit the institution consistently and maintain beneficial relationships with health care providers. Such patients are also likely to show high compliance with their prescribed treatment plans and maintain positive relationships with medical staff with less chance of legal sue for practice, which may ultimately facilitate their collaboration with health care providers ${ }^{6}$. For these reasons, hospitals providing tertiary care services regard customer satisfaction as a crucial determinant of institutional viability and make efforts to respond flexibly to changing health care environments and the public's health care needs.
Majority respondents are younger age group. In this study most of the age group are in 21 to 25 years of age which is $52(26.1 \%)$ cases. The services of doctors were highly satisfied. The services of nurses are only satisfactory.

Table 3: Opinion of the respondents about service of Nurse

\begin{tabular}{lcc}
\hline Level of Satisfaction & Frequency & Percent \\
\hline Highly Satisfied & 76 & 38.2 \\
Satisfied & 111 & 55,8 \\
Poorly satisfied & 12 & 6,0 \\
Total & $\mathbf{1 9 9}$ & $\mathbf{1 0 0 . 0}$ \\
\hline
\end{tabular}

The waiting time was satisfied less than 2 hours. The hospital environment was also satisfactory to the women attending in the OPD of the Obstetrics \& Gynecology at Dhaka Medical College, Dhaka. This result indicates that patients waiting in the OP D for seeking health services are still well delivered. Few women are poorly satisfied over the waiting time in more than 3 hours.

Table 4: Opinion of the respondents about waiting time

\begin{tabular}{lcc}
\hline Level of Satisfaction (hours) & Frequency & Percent \\
\hline Highly Satisfied/1 hour & 30 & 15.1 \\
Satisfied $/ 2$ hours & 143 & 71.9 \\
Poorly satisfied/3 hours & 26 & 13.0 \\
Total & $\mathbf{1 9 9}$ & $\mathbf{1 0 0 . 0}$ \\
\hline
\end{tabular}

Patient satisfaction is evaluated on the basis of both providerand client-focused aspects. While provider-focused aspects refer to the provision of sound medical skills, client-focused aspects are centered on the extent to which the patients feel their needs and expectations are being met during the provision of health care services ${ }^{7}$. Previous researches have reported that gaps between these aspects exist ${ }^{8}$, suggesting that identifying factors affecting perceived customer satisfaction is critical for providing quality care. To improve the patient's satisfaction most of the patient suggested for more doctors and supporting staff, improvement of wasting room facilities, cafeteria clean water supply toilet facilities should be done. Drug supply and laboratory investigations should be ensured.

Table 5: Opinion of the respondents about setting of environment

\begin{tabular}{lcc}
\hline Level of Satisfaction (hours) & Frequency & Percent \\
\hline Highly Satisfied/1 hour & 24 & 12.1 \\
Satisfied $/ 2$ hours & 127 & 63.8 \\
Poorly satisfied/3 hours & 48 & 24.1 \\
Total & $\mathbf{1 9 9}$ & $\mathbf{1 0 0 . 0}$ \\
\hline
\end{tabular}

The Government of Bangladesh should provide well equipped furniture with sitting facilities and well ventilated space. There should be a available clean water supply, toilet facilities cafeteria for best services. Satisfaction of patients depends on behaviors of the physician. Attained stillness is very import to satisfy the patients in this set up. This study attempts to identify the factors that influences faction the patients. 
Regarding the service of doctors respondent's opinion was highly satisfied (65.8) and poor satisfactory was only $0.5 \%$ cases. Regarding the services of Nurses respondent's opinion was only satisfied about $111(55.8 \%)$ cases. Regarding the opinion waiting time of respondent's cases about $143(71.9 \%)$ cases was about 2 hours.

\section{Conclusion}

In conclusion majority respondents have given the answer regarding highly satisfaction over the treatment given by the doctors. Furthermore the service delivery given by the nurses is also satisfactory to the women attending in the OPD of the Obstetrics \& Gynaecology Department at a tertiary care hospital in Dhaka.

\section{References}

1. Patient satisfaction with health service in Bangladesh. Health policy plan 2007;22(4):263-273
2. Service quality perceptions and patient satisfaction study of hospitals in a developing country. Social Science \& Medicine 2001;52(9):1359-1370

3. Customers care service relationship a empirical test of model of service quality, satisfaction and relationship oriented outcome. International $\mathrm{J}$ Service Industry Management 2010;9(2):155-168

4. Health service delivery in china a literature review Karen Eggleston Leng Meng Dingyme 2008;17(2):149-165

5. Ham, Hye-Sook, et al. "Predictors of Patient Satisfaction with Tertiary Hospitals in Korea." Nursing research and practice 2015 (2015).

6. Margolis SA, Al-Marzouqi S, Revel T, and Reed RL. Patient satisfaction with primary health care services in the United Arab Emirates. International Journal for Quality in Health Care 2003; 15(3): 241-249

7. Al-Sakkak MA, Al-Nowaiser NA, Al-Khashan HI, Al-Abdrabulnabi AA, and Jaber RM. Patient satisfaction with primary health care services in Riyadh. Saudi medical journal 2008; 29(3): 432-436

8. Bojar I, Ostrowski T, and Sapů,a R. [Patients' satisfaction with primary health care services]. Wiadomosci lekarskie (Warsaw, Poland: 1960) 2001; 55: 54-60. 